\title{
BMJ Open Assessing beliefs and risk perceptions on smoking and smoking cessation in immigrant Chinese adult smokers residing in Vancouver, Canada: a cross-sectional study
}

\author{
J Mark FitzGerald, ${ }^{1}$ Iraj Poureslami, ${ }^{2}$ Jessica Shum ${ }^{2}$
}

To cite: FitzGerald JM, Poureslami I, Shum J. Assessing beliefs and risk perceptions on smoking and smoking cessation in immigrant Chinese adult smokers residing in Vancouver, Canada: a cross-sectional study. BMJ Open 2015;5:e006435. doi:10.1136/bmjopen-2014006435

- Prepublication history and additional material is available. To view please visit the journal (http://dx.doi.org/ 10.1136/bmjopen-2014006435)

Received 21 August 2014 Revised 28 December 2014 Accepted 30 December 2014

CrossMark

For numbered affiliations see end of article.

Correspondence to Dr J Mark FitzGerald; mark.fitzgerald@vch.ca

\section{ABSTRACT}

Objectives: We aimed to conduct culturally-based participatory research to assess cultural and belief contexts for smoking behaviours within Mandarin and Cantonese communities. Outcome variables were smoking-related knowledge, smoking patterns, attitudes and beliefs, and perceived barriers and facilitators to successful cessation.

Design: A community-based approach was applied involving smokers, community key-informants and professionals in study design and implementation. Initially, focus groups were conducted and findings were used to develop study instrument. Participants responded once to study questionnaire after informed consent.

Setting: Community based in the Greater Vancouver Area, Canada.

Participants: 16 Chinese smokers participated in focus groups and subsequently, 167 current Chinese immigrant (137 males and 30 females) smokers from Mandarin and Cantonese communities, recruited with the help of community agencies and collaborating physicians, were enrolled in a cross-sectional study.

Results: We found that a majority believed smoking was harmful on their health. Younger smokers ( $<35$ years of age) did not mind smoking in front of young children compared to older smokers $(\geq 35$ years of age) $(p<0.001)$. People with high school or lower levels of education believed that they would benefit more from smoking than suffering from withdrawal symptoms compared to better educated smokers $(p<0.05)$. Mandarin smokers were significantly more likely to encourage others to quit than Cantonese smokers $(p<0.05)$. Many indicated not receiving adequate support from care providers and lack of access to culturally and linguistically appropriate cessation programmes impacted on their ability to quit smoking.

Conclusions: Our study highlighted the importance of tobacco beliefs and perceptions among Mandarin and Cantonese speaking immigrants with limited access to healthcare information and for younger smokers whose attention to health consequences of smoking may be limited as well. Study participants were generally aware

\section{Strengths and limitations of this study}

- We undertook a community-based participatory approach, with community key-informants and healthcare providers being heavily involved in all aspects of the study such as design, instrument development, implementation, community outreach and dissemination. These key-stakeholders are important allies in developing culturally and linguistically appropriate smoking cessation interventions.

- Our study provides evidence that attitudes and beliefs towards cigarette smoking differ between groups based on language, age, and gender. The differences with regards to tobacco smoking appear to be related to attitudes or knowledge.

- The results build a window of opportunity to promote tailored cessation interventions incorporating cultural beliefs, perceptions, and practices for Chinese immigrant communities.

- We used a convenience sampling method, which may not reflect the actual smoking prevalence and patterns of Chinese Mandarin and Cantonese immigrants in the Greater Vancouver Area.

- All responses were by self-report and validation of smoking behaviours or reasons to quit or continue smoking was not possible with a crosssectional design.

of the health risks and were willing to quit. Access to appropriate cessation programmes would fulfil their willingness.

\section{BACKGROUND}

Tobacco use remains the leading cause of preventable morbidity and mortality in the world. ${ }^{1-3}$ In Canada, its use has been declining slower than expected in spite of increased taxation on cigarettes and more stringent tobacco policies put into place. ${ }^{3}$ 
In order to accomplish the goal of reducing the rate of smokers among Canadian adults, smoking has to be addressed among all subpopulations, especially those with a higher smoking prevalence than the general population. Global studies have shown that those who stop smoking greatly reduce their risk of developing cardiopulmonary disease and that in general the longer the period of cessation, the greater is the reduction in risk. ${ }^{45}$ Minority and immigrant communities in Canada may be at greater risk of smoking-related illnesses. ${ }^{6}$ Reasons include lack of knowledge and awareness about the link between smoking and lung disease ${ }^{7}$; limited access to smoking cessation programmes due to cultural, language, and systemic barriers; ${ }^{8}$ and smoking behaviours. $^{9} 10$ In addition, many immigrants from low-and-middle-income countries have had prior significant exposure to biomass and biofuel as well as smoking which further increases their risk. ${ }^{11}$ This is particularly true among immigrants from Mandarin and Cantonese speaking communities (the largest immigrant minority groups living in the $\mathrm{BC}$ and Canada) ${ }^{12}{ }^{13}$ where smoking rates remains high. ${ }^{9}{ }^{10}$ Such extensive tobacco use among immigrants may be due to the fact that smoking is a largely integrated into the Chinese male culture. ${ }^{14}$ Nearly two of every three adult men in China are smokers. ${ }^{15}{ }^{16}$ It is, therefore, empirically relevant to try to understand this immigrant group's smoking knowledge, behaviours, and habits and develop culturally appropriate educational and counselling services to improve tobacco prevention attempts and promote cessation. Maximising tobacco control for newcomers requires a special understanding of smoking pattern and beliefs of new immigrant populations. The objectives of this study were: (1) to explore smoking use patterns, smoking-related knowledge, beliefs and attitudes, and perceived barriers and facilitators to smoking cessation among Mandarin and Cantonese speaking communities living in the Greater Vancouver Area (GVA), and (2) to assess the effectiveness of sociocultural and environmental factors which influenced the onset of smoking and smoking habits (continued smoking) among the study participants. We were also interested to identify differences in aforementioned variables between men and women, Mandarin and Cantonese, and between age and education level groups. The identification of tobacco use and other related patterns may help facilitate the development of community-based culturally appropriate interventions targeting tobacco use and would be helpful for future research for Chinese immigrants.

\section{METHODS}

Project design

This multistage cross-sectional study employed qualitative and quantitative components within an over-arching community-based participatory framework. The first stage comprised the development and testing of a measurement instrument for the survey study. The second stage was a quantitative study assessing the outcome variables including smokers' awareness of smoking and its cessation, attitudes and beliefs about smoking harms and benefits, and cultural norms of smoking in their community.

The study was conducted between January 2013 and June 2014, allowing for participation and collaboration between members of the Mandarin and Cantonese communities and other key-stakeholders such as professionals and researchers in the research process. ${ }^{17-19}$ Connections and networking were built with community key-informants and community agencies (eg, SUCCESS (United Chinese Community Enrichment Services Society), Vancouver Coastal Health community organisations, etc.) supporting active involvement and contribution in study design, development and implementation. Community collaborators provided assistance with recruitment of Mandarin and Cantonese smokers as well as input and suggestions on the development of focus group and interview questions. They recruited two men and two women who were members of the community, fluent in Mandarin and Cantonese, to work in alliance with four female bilingual Chinese research assistants. All community facilitators and research assistants received appropriate training prior the study. The training included approaches on how to best recruit study participants, understanding of the project's goals and objectives, how to conduct focus groups and individual interviews with smokers from their own communities, and ideas on how the team could work together effectively in collection of the best information possible on Chinese smokers' knowledge, beliefs and attitudes about harms and benefits of smoking, and socio-cultural and environmental factors affecting smoking and smoking cessation. The community researchers transcribed and translated focus group and interview discussions and we applied the collected information in the development of a study measurement tool and conceptual framework. In addition, findings from our previous qualitative smoking study (conducted with smokers from the same communities) were used in the development of the study design and measurement tool..$^{20}$

All participants signed a written consent form in their preferred written language (Chinese Simplified, Chinese Traditional, or English) translated by the bilingual researchers who clearly explained the study rationale, goals and objectives, and how their involvement would be like prior to the study.

\section{Study measurement tool}

We initially developed the study measurement tool by determining whether any English or Chinese language questionnaires were currently in use to assess attitudes and beliefs re smoking in the Chinese community. A literature search and an informal survey of immigrantserving community agencies did not find any such instrument that has been developed in Canadian Chinese context. Given the absence of a validated 
assessment questionnaire in the target languages for Canadian Chinese, a new measurement tool was developed over a 4-month period. Development of the study measurement tool began with information collected from initial focus group session participants $(n=14)$ and individual interviews $(n=2)$, review of relevant literature that addressed knowledge of, attitudes to, and behaviours in relation to tobacco use, and also our previous smoking-related qualitative studies with Mandarin and Cantonese current and ex-smokers. ${ }^{20}$ Moreover, a professional measurement tool developer (a PhD in the sociopsychology research and evaluation field from University of British Columbia) with expertise in developing mixed open-ended and closed-format questionnaires was involved in the face and content validation and finalisation of the measurement tool. The team and the measurement developer have the expertise to identify and differentiate between beliefs, attitudes and perceptions, as well as the sociocultural and environmental aspects of smoking and its cessation. Each set of variables were identified and separated by heading-title in the questionnaire. The internal consistency of the data was checked by test-retesting reliability, where the study questionnaire was administered to five smokers and tested again a week after and the results of the initial assessment and retest were compared. Also, more advanced process was applied by calculating Cronbach $\alpha$ and a coefficient was (0.89).

The final questionnaire covered current smoking knowledge, beliefs and attitudes about smoking and its cessation, and sociocultural and environmental factors that promote or prevent smoking onset and continuation. The tool included 70 questions covering demographics and concepts on smoking onset, smoking characteristics, perceptions, experience in quitting, social relationships and cultural and environmental influences and were in the format of yes/no, true/false, multiple choice, and open-ended questions (The study measurement tool can be found as online supplementary file 1 ). The questionnaire was also reviewed by a number of key-informants and health practitioners $(n=9)$ from the target communities who provided feedback and comments re the questionnaire and checked its face and content validity. The bilingual Chinese research assistants worked collaboratively together translating the study measurement tool to Chinese Simplified and Traditional formats. The translations were reviewed by secondary (back-up) translators from the target communities who were introduced by the collaborating immigrant agencies for accuracy and correctness. The tool was then reviewed by the community key-informants and professionals for further crosschecking. Finally we pilot tested the questionnaire with selected smokers and ex-smokers from the Chinese communities $(n=5)$ to confirm validation of the measurement tool and for cultural relevance and clarification, as well as translation purposes including understandability, acceptability and applicability. Suggestions were integrated into a revised version.

\section{Participant recruitment}

Eligibility criteria for participants were adults ( $\geq 21$ years old) who were current smokers (defined by having smoked at least five cigarettes per day during the past 30 days), Chinese descent (either Mandarin or Cantonese speaking) and be immigrants to Canada or children of Chinese immigrants. Participants were recruited from within the communities using a variety of outreach methods such as posting flyers and referral applied from previous studies and through network with community agency collaborators. ${ }^{17} 2122$ In total, 16 Chinese smokers participated in initial focus groups and interviews and subsequently 167 (137 males and 30 females) were interviewed, from which 93 were Mandarin speaking and 73 were Cantonese speaking. In terms of age category, 90 participants were $<35$ years of age and 76 were $\geq 35$ years of age. Our intended sample size was 150 Chinese smokers aiming to identify mean differences in knowledge, beliefs, attitudes and practices related to smoking and experience in smoking cessation between age, gender, education and ethnicity groups.

\section{Data collection}

Data were collected through administration of study questionnaire via individual interviews. Interview sessions were conducted at places and times of convenience for participants: for example, participants' homes, community centres, and our research centre. Printed consent forms were explained and signed preceding the interview. Modest honoraria were paid to cover time, travel and parking expenses. Community research assistants conducted the interviews in Mandarin or Cantonese and the participants filled in a self-reported Chinese Simplified and Chinese Traditional questionnaire while the research assistants were available to answer any questions that they would have had, or ask the responders to elaborate the given information in the open-ended questions. Each interview was conducted by two interviewers: one with an academic perspective (a research assistant), and one from community who acted as a facilitator. The two interviewers took notes during interviews including verbal and non-verbal communication by the participants and reviewed their notes at the end of each interview aiming to improve the accuracy of the information, capturing smokers' smoking beliefs, perceptions, and also their comments about cultural images of smoking and its cessation. In some instances (eg, old smokers or low literate people), the research assistants assisted by administered the study questionnaire verbally while taking notes throughout the entire interview.

\section{Data analysis}

SPSS V.20 (2012) was used for all statistical tests. Descriptive statistical tests were used and the results were presented in tables and graphs. Relevant inferential statistics were calculated for the entire sample and stratified according to age, gender, level of education, language of origin and smoking practices. The data were not 
normally distributed, and non-parametric tests were therefore used; for example, $\chi^{2}$ test for nominal data, Mann-Whitney test for ordinal data with two groups, and Kruskal-Wallis test for more than two groups with ordinal data. Binary logistic regression was used to determine the effects of demographics on the outcome variables. All data were examined regarding distributions and trends in the data, and the level of significance was set at the $\mathrm{p}<0.05$ level.

\section{Sample size calculation}

With a total sample size of 167 participants for the crosssectional study, we estimated that we could identify mean differences between different age, gender, language and education level groups and with an effect size of 0.45 with $80 \%$ statistical power and a two-sided significance level of $\mathrm{p}<0.05$.

\section{FINDINGS}

Between May 2013 and April 2014, we recruited and enrolled 167 current smokers. Table 1 describes characteristics of the study sample for Mandarin (55.7\%, $\mathrm{n}=93$ ) and Cantonese $(44.3 \%, \mathrm{n}=74)$. The participants included predominately males $(82 \%, \mathrm{n}=137)$. The median age was 35 and we used this cut-off point for younger/older groups, as used previously from our qualitative studies conducted with Chinese community smokers, ${ }^{20}$ allowing us to identify these differences in perspective.

\section{Smoking-related knowledge and reasons for starting smoking}

Knowledge of smoking consequences is an important factor to consider when designing smoking cessation programmes or implementing health promotion interventions, especially to prevent onset of smoking among young people. ${ }^{2}{ }^{8}$ Almost an equal number $(23 \%)$ of Mandarin and Cantonese smokers indicated that they were not aware of smoking side effects when they started smoking. Table 2 provides the breakdown of smoking-related knowledge by gender, age, language

\begin{tabular}{lrl} 
Table 1 Participant characteristics & & \\
\hline & N & Per cent \\
\hline Gender & & \\
$\quad$ Male & 137 & 82 \\
$\quad$ Female & 30 & 18 \\
Language & & \\
$\quad$ Mandarin & 93 & 55.7 \\
$\quad$ Cantonese & 74 & 44.3 \\
Age & & \\
$\quad<35$ & 105 & 63 \\
$\quad 35$ & 62 & 37 \\
Education level & & \\
$\quad$ High school and below & 87 & 52 \\
$\quad$ University degree and above & 80 & 48 \\
\hline
\end{tabular}

and education level. As shown on table 2, knowledge about side effects of smoking was mixed among the participants of this study, with no statistically significant differences observed between the language, gender, age and education groups in this regard.

We also aimed to determine the sociocultural and environmental factors which influenced the onset of smoking among the study participants. ${ }^{23}$ In this study, we defined social factors as smoking during the gatherings, being offered cigarettes by peers (a cultural norm in this community), smoking to feel being accepted, etc. On average for $45 \%(\mathrm{n}=75)$ of participants, 'social factors' were a trigger to start smoking, while it was the number one trigger for male smokers and smokers with who were 35 years or over with an equal rate of $53 \%$. Although 50\% of females mentioned 'emotional factors' as a contributor to starting smoking, only 22\% (on average) of males cited these as factors for them. Likewise, 'environmental factors' were considered by only $20 \%$ of participants as a factor in starting to smoke, while $50 \%$ of Mandarin smokers mentioned environmental factors as a major trigger for them to start smoking. A smoking friend was mentioned by most of participants $(66.3 \%)$ as someone in their social network when starting smoking, compared to classmate (48.5\%), family (29\%) and work-related colleagues (28\%). An interesting observation was that $50 \%$ of female smokers in the study identified having a family member who smoked when they first started smoking.

\section{Smoking beliefs, perceptions, and attitudes}

Multiple factors affected participants to become regular smokers. For instance, for around $62 \%$ of smokers (between 100 and 104), the main reasons to smoke regularly were the beliefs that smoking 'relaxed them' and 'helped them feel less stress' as well as when 'they were having a break' or when 'they were bored'. The breakdown of the triggers to smoke based on smokers' gender, age,

Table 2 At the time you started smoking, did you know the side effects of smoking?

\begin{tabular}{|c|c|c|c|c|}
\hline & \multicolumn{2}{|l|}{ Yes } & \multicolumn{2}{|l|}{ No } \\
\hline & $\overline{\mathbf{N}}$ & Per cent & $\overline{\mathbf{N}}$ & Per cent \\
\hline \multicolumn{5}{|l|}{ Gender } \\
\hline Male & 105 & 77 & 32 & 23 \\
\hline Female & 22 & 73 & 8 & 27 \\
\hline \multicolumn{5}{|l|}{ Age } \\
\hline$<35$ & 90 & 86 & 15 & 14 \\
\hline$\geq 35$ & 38 & 62 & 24 & 38 \\
\hline \multicolumn{5}{|l|}{ Language } \\
\hline Mandarin & 72 & 77 & 21 & 23 \\
\hline Cantonese & 56 & 76 & 18 & 24 \\
\hline \multicolumn{5}{|l|}{ Education level } \\
\hline High school under & 61 & 70 & 26 & 30 \\
\hline $\begin{array}{l}\text { University degree and } \\
\text { above }\end{array}$ & 67 & 84 & 13 & 16 \\
\hline
\end{tabular}


Table 3 Reasons for becoming regular smokers

\begin{tabular}{|c|c|c|c|c|c|c|c|c|}
\hline & \multicolumn{2}{|c|}{ Relaxation } & \multicolumn{2}{|c|}{ Less stress } & \multicolumn{2}{|c|}{ Having break } & \multicolumn{2}{|c|}{ Being bored } \\
\hline & $\mathbf{N}$ & Per cent & $\mathbf{N}$ & Per cent & $\mathbf{N}$ & Per cent & $\mathbf{N}$ & Per cent \\
\hline \multicolumn{9}{|l|}{ Gender } \\
\hline Female & 22 & 73 & 14 & 47 & 17 & 57 & 16 & 53 \\
\hline Male & 82 & 60 & 81 & 59 & 83 & 61 & 84 & 61 \\
\hline \multicolumn{9}{|l|}{ Age } \\
\hline$<35$ & 73 & 70 & 62 & 59 & 69 & 66 & 68 & 65 \\
\hline$\geq 35$ & 31 & 51 & 33 & 53 & 31 & 50 & 34 & 55 \\
\hline \multicolumn{9}{|l|}{ Language } \\
\hline Mandarin & 50 & 54 & 57 & 61 & 53 & 57 & 54 & 58 \\
\hline Cantonese & 40 & 54 & 38 & 51 & 47 & 64 & 48 & 65 \\
\hline \multicolumn{9}{|l|}{ Education level } \\
\hline High school under & 51 & 59 & 45 & 52 & 52 & 60 & 55 & 63 \\
\hline University degree and above & 53 & 66 & 50 & 62 & 48 & 60 & 47 & 59 \\
\hline
\end{tabular}

language and education groups are shown on table 3, with no statistically significant differences observed between the male and female smokers, and different age, language and education groups in this regard.

We were also interested to identify the social and cultural aspects of smoking habits (continued smoking). When asked the question of whether 'most people in my culture smoke' to assess participants' perceived commonality of smoking in their communities, there was a significant difference between male and female participants $\left(\chi^{2}=5.424, \mathrm{df}=1, \mathrm{p}<0.05\right)$; more males $(\mathrm{n}=46,34 \%)$ believed that smoking was a cultural habit in their community than females $(n=17,57 \%)$ did. Similar findings were observed between Mandarin and Cantonese $\left(\chi^{2}=5.182, \quad \mathrm{df}=1, \quad \mathrm{p}<0.05\right) ;$ more Mandarin $\quad(\mathrm{n}=65)$ answered yes to the question than Cantonese smokers $(n=39)$. Many participants $(61 \%)$ indicated they normally smoked when they were 'with friends'; with the highest proportion reported among the <35 years old participants $(82 \%)$ and male participants $(70 \%)$. Remarkably, $70 \%$ of the $<35$ years old participants indicated they smoked when they had alcohol. The rate was $60 \%$ among female participants, $57 \%$ among males, and $57 \%$ among both Mandarin and Cantonese smokers. In terms of attitudes towards exposing others to second or third-hand smoke, we asked participants 'do you mind smoking in front of non-smokers'? Younger smokers ( $<35$ years of age) were more likely $(n=72)$ to mention that they did not mind smoking in front of non-smokers compared to older smokers ( $\geq 35$ years of age) $(n=52)$. The mean difference was significant $\left(\chi^{2}=7.133, \mathrm{df}=1\right.$, $\mathrm{p}<0.01)$. Also, when the participants were asked whether they minded smoking in front of young children, similarly, more younger smokers ( $<35$ years of age) $(n=97)$ mentioned that they 'did not mind smoking in front of young children' than the older smokers $(\mathrm{n}=55)$ and the difference was significant $\left(\chi^{2}=5.123, \mathrm{df}=1, \mathrm{p}<0.05\right)$. We also aimed to assess smokers' viewpoints regarding second hand smoking and its harm. We asked whether 'second and third hand smoke was as harmful as first hand smoke', again, relatively more males said 'no' when compared to female smokers $(n=40$ and $n=10$, respectively) and the difference was significant $\left(\chi^{2}=4.736, \mathrm{df}=1\right.$, $\mathrm{p}<0.05)$. Finally, we assessed smokers' beliefs about their own smoking pattern with a self-reported question of ' $I$ have a smoking routine/pattern'. No significant differences were identified between gender, age, and language groups. However, we found that more people with high school education or less mentioned they did not have a routine/pattern $(\mathrm{n}=30)$ compared to people with higher education $(\mathrm{n}=12)$ and the difference was significant $\left(\chi^{2}=7.156, \mathrm{df}=1, \mathrm{p}<0.01\right)$.

\section{Perceptions about smoking}

We assessed smokers' perceived enjoyable feeling that they may have due to smoking by asking whether 'there is a different feeling when comparing times I smoke and don't smoke' and found a statistically significant difference between male and female participants $\left(\chi^{2}=4.237 ; \mathrm{df}=1, \mathrm{p}<0.05\right)$. Significantly more males $(n=47)$ mentioned experiencing a different feeling when they smoked compared to not smoking than female smokers $(n=15)$. In addition, younger smokers ( $<35$ years of age) as well claimed to have a different feeling when comparing times smoking and not smoking $(\mathrm{n}=46)$ compared to older smokers $(\mathrm{n}=16)$, and the differences were statistically significant $\left(\chi^{2}=3.889, \quad \mathrm{df}=1, \quad \mathrm{p}<0.05\right)$. Likewise, more Mandarin smokers $(n=41)$ than Cantonese smokers $(n=20)$ reported having a different feeling when they smoke compared to when they were not smoking $\left(\chi^{2}=5.188\right.$, $\mathrm{df}=1, \mathrm{p}<0.05)$. For this outcome there was no significant differences between highly educated (college/university and above) and lower educated (high school or lower).

Additionally, we assessed smokers' perceptions about helpfulness of smoking to alleviate their anxiety and stress. We noticed that $77 \%$ of female smokers, $69 \%$ of younger smokers (aged 34 years or younger), and 52\% of older smokers (age 35 or older) smoked to reduce their sense of helpfulness. Male smokers perceived that smoking helped them to minimise the feeling of being bored $(80 \%)$ and made them more connected to their group of friends $(69 \%)$. 


\section{Smoking cessation}

We aimed to identify willingness to quit smoking and perceived barriers and facilitators to cessation. The majority of participants, in particular young male and female smokers, mentioned their desire to quit and attempted to several times, before giving up and smoking again. A few people mentioned using medications or seeking professional advice to quit smoking but mainly relied on their own willpower to quit. Also, older participants indicated trying to quit due to health-related issues such as heart disease or cancer. We were also interested to find out whether participants were under pressure by someone close to them to quit smoking. When asked "I was nagged by someone to quit smoking", no statistically significant differences were identified in different gender, age, language and education groups. However, when we asked whether they "would encourage others to quit", more Mandarin speaking smokers answered yes to $(n=45)$ than Cantonese speaking smokers $(\mathrm{n}=23) \quad\left(\chi^{2}=5.172, \mathrm{df}=1, \mathrm{p}<0.05\right)$. No significant differences were identified based on age, gender and level of education. In addition, most participants $(87 \%)$ said 'No' to the question: "Would you encourage non-smokers to smoke?" Furthermore, we also asked whether living in a smoking restricted society like Canada would encourage smokers to quit or cut down on their smoking. More Mandarin speaking smokers $(n=56,60 \%)$ mentioned that "living in Canada influenced their smoking habits or desire to quit", compared to Cantonese speaking smokers $(\mathrm{n}=30,41 \%) \quad\left(\chi^{2}=6.424, \mathrm{df}=1, \mathrm{p}=0.011\right)$.

More people with high school or lower education $(n=34)$ agreed with the statement "I would benefit more from smoking than suffering from withdrawal symptoms due to quitting", compared to the more educated smokers $(\mathrm{n}=12) \quad\left(\chi^{2}=6.102, \mathrm{df}=1, \mathrm{p}<0.05\right)$. When asked whether they "tried nicotine replacement therapy to quit smoking”, more Mandarin speaking smokers ( $\mathrm{n}=32$ ) mentioned that they had tried this aid to quit smoking compared to Cantonese speaking smokers $(\mathrm{n}=12$ $\left(\chi^{2}=7.275, \mathrm{df}=1, \mathrm{p}=0.007\right)$.

In general, participants identified language and literacy issues as barriers to accessing smoking cessation information as well as lack of useful information in a social media format. For instance, older participants mentioned that they had limited exposure to public sources of information on cessation services that were developed in their native language. A small minority of these smokers had received advice and information about the health issues attributed to smoking from their physicians. Younger smokers mentioned the lack of disseminating smoking cessation messages through social media such as text messaging to promote quitting services in their native language.

Our synthesis of the interview data identified seven barriers to the participants' cessation which are summarised in box 1 .
Box 1 Barriers to smoking cessation identified by the participants

A. The problems of managing their lives in a highly stressful environment.

B. Their isolation and the limited support systems in their community or work/school environments.

C. The availability of smoking as a social-connection to their peers and limited resources for pleasure.

D. Perceived minimal health risks of smoking.

E. The commonality of smoking in their community.

F. The scarce or non-existent information about how to stop smoking.

G. The belief that all they can quit on their own whenever they decide to.

\section{DISCUSSION}

The main goal of this study was to gain insights on the beliefs and perceptions associated with smoking behaviours and smoking cessation among Chinese Cantonese and Mandarin speaking current smokers, taking into account culturally specific knowledge and practices. The results have implications for the development of appropriate smoking cessation programmes and educational interventions to prevent and control tobacco-related health issues among the target communities. Such interventions may have policy implications in health promotion programmes to prevent smoking onset among younger population groups in the immigrant communities.

Several participants in this study indicated their desire to quit and attempted to do so many times, many of whom did it relying on their own willpower. Only a few, mainly among older smokers, tried to quit because of health-related issues. They mentioned that a better communication with primary care providers and ease of access to culturally and linguistically appropriate smoking cessation resources would promote smoking cessation in their communities. Similar findings have been reported in studies done in other countries as well as among many immigrant communities in Canada who tried to quit smoking. ${ }^{24-27}$ In addition to elucidating these barriers to smoking cessation and despite continued smoking, participants showed being knowledgeable in health related and other negative aspects of smoking as on average, $70 \%$ of the participants indicated they were aware of the health consequences of smoking. This finding has been confirmed in other studies. ${ }^{27}$ In our study, we found that higher education, better knowledge, and smoking regulations contributed to having a greater intent to quit smoking. For instance, we found that most participants were not ignorant of the dangers of smoking, with the vast majority recognising that smoking posed risks to their own health and the health of those around them. This knowledge is much higher than that of Chinese smokers who were previously surveyed in China, where only $36 \%$ of participants believed smoking can cause lung cancer and only $4 \%$ were aware of the relationship of smoking to heart disease. ${ }^{28}$ In addition, 
many of the smokers in our study already accepted limitations on the use of cigarettes in Canada, and many, mostly younger smokers, supported restrictions on indoor smoking and also mentioned not smoking at home or where children are present. This could be attributed to the smoking restriction rules as well as the strong antismoking educational campaigns in Canada. For example, since 2001, Health Canada has spent more than $\$ 480$ million for a 5-year programme to encourage tobacco cessation programmes for all Canadians. ${ }^{29}$ These regulations might be important to reduce the risk of second-hand and third-hand smoking and related health issues among young children and other nonsmoker family members.

In terms of reasons to continue smoking, perceived advantages of smoking such as 'smoking does make me feel more comfortable' and 'smoking helps me to be stress-free when I have problems' appeared to be more important factors to promote smoking continuation among our study participants than perceived disadvantages around 'health issues' and 'money' which shown to be strong motivators in quitting smoking in some studies. Some studies found that smokers may not be aware of the diseases caused by smoking and therefore, they may perceive themselves less susceptible to the risks of smoking. ${ }^{29-33}$ For instance, health consequences and costs of smoking were not perceived as strong motivators to quit smoking among young participants. They reported the stimulating and antistress effects of smoking (smoking may actually made them feel happier, more alert, etc), the feelings that may reinforce their tobacco use and have associated these feelings with being around other smokers. In older smokers, most of which showed low self-efficacy on being able to quit, the rationale for continuing to smoke was different. For instance, for over $16 \%$ of smokers in this age group the disadvantages of quitting were perceived to outweigh its advantages. Some reasons mentioned by older participants were: the addiction of nicotine, being too late to quit, and that their body needed nicotine. In other studies among mainstream populations, self-efficacy expectations and advantages of smoking cessation appeared to be the most important associates of quitting smoking among older smokers. ${ }^{34}{ }^{35}$ Therefore, this issue should be revisited in future studies with ethnocultural communities. The results of this study suggest that understanding health beliefs and perceptions around smoking and improving self-efficacy are useful tools in promoting smoking cessation among smokers in Chinese immigrant communities.

\section{Limitations}

Some limitations need to be considered. First, this study used a convenience sample, so it may not reflect the actual smoking prevalence and patterns among Mandarin and Cantonese immigrants in the GVA. We could not explore the effect of acculturation on smoking habits and patterns. There was no previous data on smoking patterns among Chinese immigrants in
Canada, and attempting a community based assessment would have been inherently difficult for an exploratory study. Therefore the findings of this study cannot be generalised to larger Mandarin and Cantonese speaking communities residing in the GVA. The goal was to explore the links to smoking cessation among Mandarin and Cantonese populations in order to gain insight into the need to adapt smoking cessation programmes in these groups. In future research, a longitudinal design in which our results can be tested is recommended. A second limitation is the fact that all responses were by self-report and validation of smoking behaviours or reasons to quit or continue smoking was not possible with a cross-sectional design. A third limitation is the absence of a native mainstream (English-speaking) reference group, due to a lack of resources. This could be a problem for interpreting the additional 'culturally specific' beliefs, because these were not elicited from mainstream population group. Nevertheless, to assess whether the beliefs we identified in this study are really 'culturally specific', a cohort study with all significant beliefs for main ethnic groups in the GVA, including mainstream population, might be useful.

\section{CONCLUSIONS}

The results of our study suggest that an effective antismoking campaign in the Chinese community should go beyond traditional English language efforts, utilise Chinese resources, and build on existing cultural attitudes (such as the belief that smoking is inappropriate for young people) and knowledge (such as health risks) about smoking. Particular attention should be paid to differences between female and male smokers and between younger and older smokers related to their knowledge, beliefs and attitudes about smoking, and perceived barriers and facilitators to smoking cessation. We also identified different beliefs and perceptions about the harms and benefits of smoking, based on language, age and gender group. The findings indicate the importance of addressing risk perceptions about the immediate and long-term consequences of smoking. Therefore, future interventions can prove the applicability of a risk perception model on smoking cessation among Mandarin and Cantonese speaking smokers. Despite finding significant differences between the genders, educational level, ethnicity and age groups in our study, we believe a larger sample size is needed to address this issue. The findings build a window of opportunity to promote tailored cessation interventions incorporating cultural beliefs, perceptions and practices for Chinese immigrant communities.

\section{Practical implications}

Our study identified the health beliefs and perceptions about smoking and its cessation among Mandarin and Cantonese immigrants that could be considered by healthcare decision makers to develop health promotion 
programmes preventing smoking onset among younger population groups in Chinese community. Interventions should take account of the specific profiles that Mandarin and Cantonese immigrants in terms of knowledge, attitudes, beliefs and perceptions on their smoking habits and patterns. Given the results of this study, we plan to conduct further research to assess the applicability of a risk perception model to the smoking behaviour of routine smokers in the target immigrant communities. The model has been shown effective in terms of modifying risk-taking behaviours, promoting positive perceptions, and improving self-efficacy that have been applied for changing smoking habits/behaviour. ${ }^{36-38}$

\section{Author affiliations}

${ }^{1}$ The Lung Centre, Gordon and Leslie Diamond Health Care Centre, Vancouver, British Columbia, Canada

${ }^{2}$ Faculty of Medicine, Respiratory Medicine Division, UBC, Centre for Clinical Epidemiology and Evaluation (C2E2), Vancouver General Hospital-Research Pavilion, Vancouver, British Columbia, Canada

Acknowledgements The authors would like to thank the community members, facilitators, ethnocultural serving agencies (SUCCESS), and key-informants from the Mandarin and Cantonese communities in the Greater Vancouver Area who helped us with all aspects of this research.

Contributors JMFG and IP planned the conception and study design. IP prepared the proposal draft to the funding agency and applied for the ethics approval. JS coordinated the study, recruited participants, and facilitated the community involvement. IP analysed and interpreted the study data. IP and JS drafted the manuscript for important intellectual content

Funding This project was funded by a community grant from The Vancouver Foundation, Vancouver, Canada (grant number UNR12-0714).

Competing interests None.

Ethics approval Ethics approval was obtained for this study from the University of British Columbia Research Ethics Board.

Provenance and peer review Not commissioned; externally peer reviewed.

Data sharing statement No additional data available.

Open Access This is an Open Access article distributed in accordance with the Creative Commons Attribution Non Commercial (CC BY-NC 4.0) license, which permits others to distribute, remix, adapt, build upon this work noncommercially, and license their derivative works on different terms, provided the original work is properly cited and the use is non-commercial. See: http:// creativecommons.org/licenses/by-nc/4.0/

\section{REFERENCES}

1. Centers for Disease Control and Prevention. Tobacco Use. 2012. http://www.cdc.gov/chronicdisease/resources/publications/aag/osh. htm (accessed 20 Jun 2014)

2. World Health Organization. Tobacco Free Initiative (TFI). 2014. http:// www.who.int/tobacco/health_priority/en/ (accessed 18 Jun 2014).

3. Haddad L, El-Shahawy O, Shishani K, et al. Cigarette use attitudes and effects of acculturation among Arab immigrants in USA: a preliminary study. Health 2012;4:785-93.

4. Robles Gl, Singh-Franco D, Ghin HL. A review of the efficacy of smoking-cessation pharmacotherapies in nonwhite populations. Clin Ther 2008;30:800-12.

5. Okuyemi K, Nollen N, Ahluwalia J. Interventions to facilitate smoking cessation. Am Fam Physician 2006;74:2620271.

6. Health Canada. Canadian Tobacco Use Monitoring Survey (CTUMS) 2010. 2010. http://www.hc-sc.gc.ca/hc-ps/tobac-tabac/ research-recherche/stat/ctums-esutc_2010_graph-eng.php (accessed 2 Jul 2014).

7. Yan J, Xiao S, Ouyang D, et al. Smoking behavior, knowledge, attitudes and practice among health care providers in Changsha city, China. Nicotine Tob Res 2008;10:737-44.

8. Wu D, Ma GX, Zhou K, et al. The effect of a culturally tailored smoking cessation for Chinese American smokers. Nicotine Tob Res 2009;11:1448-57.

9. Chen W. Susceptibility to Smoking among Chinese-Canadian Non-smoking Adolescents [Doctoral Dissertation]. University of British Columbia, 2008. https://circle.ubc.ca/bitstream/handle/2429/ 942/ubc_2008_fall_chen_weihong.pdf?sequence=1 (accessed 2 Jul 2014).

10. Yang G, Ma J, Liu N, et al. Smoking and passive smoking in Chinese2002. Zhonghua Liu Xing Bing Xue Za Zhi 2005;26:77-83.

11. Ksal H, Sayg A, Sariman N, et al. Evaluation of clinical and functional parameters in female subjects with biomass smoke exposure. Respir Care 2013;58:424-30.

12. Statistics Canada. Some facts about the demographic and ethnocultural composition of the population. 2008. http://www. statcan.gc.ca/pub/91-003-x/2007001/4129904-eng.htm\#2 (accessed 2 Jul 2014).

13. BC Statistics. Population Estimates-Total Populations. 2010. http:// www.bcstats.gov.bc.ca/data/pop/pop/estspop.asp\#totpop (accessed 2 Jul 2014)

14. Zeng XX, Chiu $\mathrm{CH}$, Sun J, et al. A phone-counseling smokingcessation intervention for male Chinese restaurant workers. J Commun Health 2010;3:1-12.

15. Gallup World. Three in 10 Chinese Adults Smoke. 2012. http://www. gallup.com/poll/152546/three-chinese-adults-smoke.aspx (accessed 2 Jul 2014).

16. World Health Organization. Tobacco in China. Western Pacific Region. 2014. http://www.wpro.who.int/china/mediacentre/factsheets/ tobacco/en/ (accessed 20 Jun 2014).

17. Poureslami I, Doyle-Waters MMR, Nimmon L, et al. Hearing the community voice: methodological issues in developing asthma self-management educational materials for immigrant communities. In: Agyemang C, Airhihenbuwa CO, de-Graft Aikins A, eds. Ethnicity: theories, international perspectives and challenges. Hauppage, NY: Nova Publishers, 2014:125-56.

18. Faridi Z, Grunbaum JA, Gray BS, et al. Community-based participatory research: necessary next steps. Prev Chronic Dis 2007 http://www.cdc.gov/pcd/issues/2007/jul/06_0182.htm (accessed 21 Jun 2014).

19. Israel BA, Schulz AJ, Parker EA, et al. Review of community-based research: assessing partnership approaches to improve public. Annu Rev Public Health 1998;19:173-202.

20. Poureslami I, Shum J, Cheng N, et al. Does culture or illness change a smoker's perspective on cessation? Am J Health Behav 2014;38:33-9.

21. Poureslami I, Rootman I, Doyle-Water MMR, et al. Health literacy, language, and ethnicity-related factors in newcomer asthma patients to Canada: a qualitative study. J Immigr Minor Health 2011;13:315-22.

22. Klassen AF, Gulati S, Watt L, et al. Immigrant to Canada, newcomer to childhood cancer: a qualitative study of challenges faced by immigrant parents. Psycho-oncol 2012;21: 558-62.

23. Scarinci IC, Silveira AF, Figueiredo dos Santos D, et al. Sociocultural factors associated with cigarette smoking among women in Brazilian worksites: a qualitative study. Health Promot Int 2007;22:146-54.

24. Dawson AP, Cargo M, Stewart $\mathrm{H}$, et al. Aboriginal Health Workers experience multilevel barriers to quitting smoking: a qualitative study. Int J Equity Health 2012;11:27.

25. North American Quitline Consortium (NAQC). The Use of Quitlines among Priority Populations in the U.S.: Lessons from the Scientific Evidence. 2011. http://c.ymcdn.com/sites/www.naquitline.org/ resource/resmgr/Issue Papers/IssuePaperTheUseofQuitlinesA.pdf (accessed 15 Jul 2014)

26. Maryland Department of Health and Mental Hygiene. Exploring cultural, psychosocial, and environmental factors influencing tobacco use among Asian Americans, Hispanics, African Americans and American Indians in Maryland. Cigarette Restitution Fund's Tobacco Use Prevention and Cessation Program. 2008. https://sph.umd.edu/ epib/cultural_competency/Exploring\%20cultural,\%20psychosocial,\% 20 and $\% 20$ environmental\%20factors\%20influencing $\% 20$ tobacco\% 20use \%20among\%20Asian\%20Americans, \%20Hispanics, \% 20 African $\% 20$ Americans $\% 20$ and $\% 20$ American $\% 20$ Indians $\% 20$ in $\%$ 20Maryland.pdf (accessed 15 Jul 2014). 
27. Binnal A, Rajesh G, Ahmed J, et al. Insights into smoking and its cessation among current smokers in India. Asian Pacific $J$ Cancer Prev 2013;14:2811-18.

28. Yang J, Hammond D, Driezen P, et al. Health knowledge and perception of risks among Chinese smokers and non-smokers: findings from the Wave 1 ITC China Survey. Tob Control 2010;19 (Supplement 2):i18-23.

29. Siahpush M, McNeill A, Hammond D, et al. Socioeconomic and country variations in knowledge of health risks of tobacco smoking and toxic constituents of smoke: results from the 2002 International Tobacco Control (ITC) Four Country Survey. Tob Control 2006;15 (Suppl III):iii65-70.

30. Oncken C, McKee S, Krishnan-Sarin S, et al. Knowledge and perceived risk of smoking-related conditions: a survey of cigarette smokers. Prev Med 2005;40:779-84.

31. Roddy E, Antoniak M, Britton J, et al. Barriers and motivators to gaining access to smoking cessation services amongst deprived smokers-a qualitative study. BMC Health Serv Res 2006; 6:147-54.

32. Litmus research organization. Quitting Motivations and Barriers Qualitative Research. The Quit Group. 2005. http://www.quit.org.nz/
file/research/FINAL\%20Litmus\%20report-Quitting\%20Motivations\% 20and\%20Barriers.pdf (accessed $15 \mathrm{Jul} 2014$ ).

33. Richardson K. Smoking, Low Income and Health Inequalities: Thematic Discussion Document. Action on Smoking and Health and the Health Development Agency. 2001. http://www.ash.org.uk/files/ documents/ASH_86.pdf (accessed 15 Jul 2014).

34. Gwaltney CJ, Metrik J, Kahler CW, et al. Self-Efficacy and smoking cessation: a meta-analysis. Psychol Addict Behav 2009;23:1-20.

35. Dijkstra A, De Vries H. Self-efficacy expectations with regard to different tasks in smoking cessation. Psychol Health 2000;15: 501-11.

36. Song AV, Morrell HE, Cornell JL, et al. Perceptions of smoking-related risks and benefits as predictors of adolescent smoking initiation. Am J Public Health 2009;99:487-92.

37. Aryal UR, Petzold M, Krettek A. Perceived risks and benefits of cigarette smoking among Nepalese adolescents: a population-based cross-sectional study. BMC Public Health 2013;13:187-96.

38. Harris JK, Karamehic-Muratovic A, Herbers SH, et al. Perceptions of Personal Risk About Smoking and Health Among Bosnian Refugees Living in The United States. J Immigrant Minority Health 2012;14:413-919. 